This is the post print version of the article, which has been published in has been published in Patient Education and Counseling, 89(1) pp.38-43, 2012 by Elsevier. https://doi.org/10.1016/i.pec.2012.04.009

(C) 2012. This manuscript version is made available under the CC-BY-NC-ND 4.0 license http://creativecommons.org/licenses/by-nc-nd/4.0/

\title{
Engaging parents through gaze: Speaker selection in three-party interactions in maternity clinics
}

\author{
Sanni Tiitinen ${ }^{1}$ \& Johanna Ruusuvuori ${ }^{1,2}$ \\ 1 School of Social Sciences and Humanities, University of Tampere, Finland \\ 2 Finnish Institute of Occupational Health, Finland
}

\begin{abstract}
Objective: Describing and analyzing speaker selection in conversations between the health nurse and parents in maternity clinics.

Methods: The data consisted of ten video-recorded encounters in maternity clinics. Using conversation analysis, we investigated 89 sequences of interaction in which the health nurse asks a question that is verbally addressed to both parents.

Results: There was an observable pattern of selecting mothers as principal respondents by all participants of the encounters in maternity clinics. In a few deviant cases, fathers were selected as principal respondents. A typical practice of speaker selection was the gaze direction of the health nurse towards the recipient (usually the mother) at the closure of her question. Various situational elements also influenced which one of the parents answered the question. The deviant cases in which fathers were selected as principal respondents were mainly explainable by the use of the questionnaire designed to facilitate talking about psychosocial issues connected with the transition to parenthood.
\end{abstract}

Conclusion: Particular interactional circumstances and practices can break the pattern of selecting mothers as respondents to questions addressed to both parents.

Practice Implications: Fathers could easily be engaged in conversations through gaze. Also the questionnaire seems promising in engaging fathers in conversations in clinics.

Keywords: conversation analysis, gaze, maternity clinics, question-answer sequences, speaker selection, three-party interactions, transition to parenthood 


\section{Introduction}

Controlling the reproductive capacity of the population is one of the major concerns of health and social policy in Western countries. This task has traditionally included controlling the physical health of the pregnant woman and the child. Recently, increasing attention has been paid to the social and psychological aspects of having children and starting a family. The health care policies of Western countries have perceived a need for early support of parenthood [1-2]. In Finnish maternity and child health care, a principle of familycenteredness - the idea that all the family members are equally important clients - has been introduced [3]. The phase of transition to parenthood may invoke feelings of distress, anxiety and even depression for both parents [4-7]. To be able to offer psycho-social support, it is essential to create a confidential client relationship between the health nurse and the parents. However, previous research suggests that fathers often feel left out in maternity and child health care clinics [8-11]. In our view, taking both parents along as competent participants in conversation is a prerequisite for being able to support them in the transition to parenthood.

Our point of departure is that the more or less permanent roles and positions that mothers and fathers develop as parents are grounded in their actions (talk and non-verbal conduct) in immediate face-to-face interaction [12-13]. In this study, we conducted a conversation analysis of speaker selection by health nurses to engage parents in conversations in maternity clinics. By investigating the activities of participants in interaction with the help of videorecordings from authentic encounters in maternity clinics, we hoped to discover some basic mechanisms of interaction that may influence the identity-work that participants constantly do in adopting their roles as mothers and fathers.

In Finland, virtually all expectant parents and families with children under the age of six attend the maternity and child health care clinics in which the progress of the pregnancy and the growth and development of the child are controlled by a health nurse and a doctor. Using these preventative public services is voluntary and free of charge. [14-15] The data for this research was collected in the clinics that were implementing a new practice of family-centered care. This intervention included e.g., a questionnaire designed to facilitate talking about psycho-social issues connected with the transition to parenthood.

Health care encounters have largely been studied using quantitative coding of the verbal and non-verbal behavior of professionals and patients in communication categories [16-18]. These studies have provided valuable overviews on how certain interactional patterns are related to certain background variables. They have not, however, addressed the actual interactional practices through which one party is able to influence the other within health care encounters. [19] In this study, we used a qualitative and sequential method conversation analysis - to analyze the data and quantitative categorization to organize it. We described in detail the trajectory of interaction, a question-answer sequence, in which the health nurse asks a question that is verbally addressed to both parents and one of the parents answers. We examined the interactional practices and circumstances that seem to influence speaker selection following the health nurse's question. We focused on the gaze direction which according to previous research, is one possibly relevant practice in speaker selection [20-23]. 


\section{Methods}

\subsection{Data}

The data of this article consisted of ten video-recorded encounters between a health nurse and expectant parents in Finnish maternity clinics. All client couples were expecting their first child, but the phase of the pregnancy varied. The data were from encounters with eight female health nurses in four maternity clinics. The collection of data was approved by the ethical board of the city administering the clinics. Participants were informed that the research concerns interaction between clients and professionals; no detailed information on the research problem was provided. Informed consent to video-recording was acquired from all participants.

We collected all the sequences of interaction in which the health nurse addresses a question to both parents using the plural person reference you, "te". (In Finnish there are separate person references for you in singular "sinä" and in plural "te".) Only sequences in which the gaze direction of the health nurse was evident were included $(n=89)$. The questions addressed issues such as the parents' ways of life (hobbies, diets, using intoxicants), family relationships, psycho-social issues and practical arrangements related to visiting the maternity clinic. We considered as questions the health nurse's turns that the parents interpreted as questions. This interpretation became observable as they answered the question [24].

Using the plural person reference, the health nurse treats both parents as competent to answer the question [see 25-26]. In our view, one parent's decision to take the opportunity to respond may result from particular features in the formulation, presentation or context of the question.

\subsection{Analysis}

The analysis proceeded in two phases. First, we used cross-tabulation to organize the data. Drawing upon previous knowledge on the significance of gaze direction in speaker selection [20-23], we examined the relation between the variables: a) which one of the parents answers the health nurse's question first and b) the health nurse's gaze direction at the closure of the question. This analysis ensured that all cases verbally addressed to both parents were included in the qualitative analysis. Further, it illustrated the regularities and deviant cases within the data, and thus served as the basis for a more detailed conversation analysis (CA) of interactional practices conducted at the turn transition.

CA is based on ethnomethodological theory proposing that people construct the social world collectively by using socially shared methods [13]. These methods - the ways in which particular interactional tasks are conducted - are the primary focus of CA research. CA explores social interaction using recordings of naturally occurring interaction as data. Ordinary conversation is seen as the fundamental (default) form of interaction, as a basis for multiple institutional variations. CA has been successfully used to investigate interaction in various institutional settings, such as health care encounters since 1960's. [19, 27]

The basic proposition of CA is that conversation is structured, the communicators' actions are guided by certain generic orders that have to do with turn-taking, formation of conversational sequences based on paired interdependent actions, ways to regulate engagement and ways to maintain intersubjectivity in conversation. These structures are normative in the sense that speakers are morally accountable for not acting according to the structures. [13, 27] 
According to CA theory, the structures are universal and independent of the participants' psychological motives [28]. The theory is based on empirical analyses of naturally occurring conversations in various languages. Another fundamental proposition of CA is that every communicative action is thoroughly contextual, both orienting to the context that the previous turns have shaped, and shaping the context for the succeeding turns, in which the speakers show again an interpretation of the previous turns. [13, 27]

CA studies approach the data with analytic induction investigating both the general pattern and atypical, "deviant", cases. Accordingly, our analysis began with the description of the general pattern of interaction in sequences in which the health nurse asks a question, derived from our cross-tabulation. We then analyzed each case that departed from the general pattern separately to produce a comprehensive description of the data. According to CA theory, the typical pattern can be considered as a possible normative practice, as long as the deviant cases can be explained by situational elements and this way fit into the rule. [27, 29]

In our analysis, we focused on the structure of interaction called turn-taking organization. Interaction is composed of turns that are composed of turn constructional units (TCUs). After each TCU, there is a transition relevance place (TRP) in which the participants implicitly negotiate who speaks next. Turn-taking is regulated by certain rules, one of which is that if the speaker selects someone else to speak next, that person has a right and an obligation to do so. [30] The speaker has various techniques for turn-allocation, i.e. for selecting a particular recipient as the next speaker. One of the techniques is gazing at the recipient at the closure of the turn. [20-21, 30]

\section{Results}

The results of the quantitative categorization are in accordance with previous studies [20-23] with regard to the significance of gaze direction as a turn-allocation technique. Crosstabulation demonstrated that within our data, the health nurse's gaze direction at the closure of her question (at the transition relevance place) is statistically very significant $(p<0.001)$ in determining which one of the parents answers the question first. When the health nurse gazed at the mother, the mother answered the question first in $81 \%$ of the cases and respectively, when the gaze was at the father, he answered the question first in $65 \%$ of the cases. (See Table 1.)

As the cross-tabulation of the data displays, the gaze direction provided a statistically significant but not a comprehensive explanation for turn-allocation in each case. Next, we present the more detailed qualitative analysis to illustrate the ways in which gaze direction and other interactional elements implicate a particular parent to be the principal respondent and the ensuing interactional consequences. We began our analysis by focusing on the interactional consequences of turn-allocation, i.e., who answers the question first, and used this categorization as the starting point for the analysis. First, we present the typical cases, i.e., those in which the mother answers the question first $(n=64)$. With regard to these cases, we examine the practices used to select the mother and the circumstances in which she selfselects as the principal respondent. Second, we present the cases in which the father answers first or at the same time as the mother $(n=25)$. We illustrate how 14 of these 25 cases follow the pattern of selecting the mother as the principal respondent. We then examine the remaining 11 deviant cases to describe the interactional elements that explain the exception from this pattern. 
Table 1: The health nurse's (HN) gaze at the transition relevance place (TRP) and which of the parents answers first (89 interaction sequences), $\chi^{2}=24.4$ (all categories included, $\mathrm{n}=89$ ), $\mathbf{p}<0.001 ; \chi^{2}=17.9$ (without categories "at the same time" and "other", $\mathrm{n}=60$ ), $\mathrm{p}<0.001$

Health nurse's gaze at the TRP

\begin{tabular}{ccccccccc} 
Which one of the parents & \multicolumn{3}{c}{ Mother } & \multicolumn{2}{c}{ Father } & \multicolumn{2}{c}{ Other* } & \multicolumn{2}{c}{ total } \\
\cline { 2 - 9 } answers first? & Freq. & $\%$ & Freq. & $\%$ & Freq. & $\%$ & Freq. & $\%$ \\
\hline Mother & 38 & 81 & 4 & 23 & 22 & 88 & 64 & 72 \\
Father & 7 & 15 & 11 & 65 & 2 & 8 & 20 & 22 \\
At the same time & 2 & 4 & 2 & 12 & 1 & 4 & 5 & 6 \\
\hline total & 47 & 100 & 17 & 100 & 25 & 100 & 89 & 100 \\
\hline \% within HN's gaze & & 53 & & 19 & & 28 & 100 & \\
\hline
\end{tabular}

* In the categories of the health nurse's gaze direction, "other" refers to the situations in which the health nurse does not look at either of the parents but, e.g., the computer screen or papers.

\subsection{The mother answers first $(n=64)$}

As Table 1 illustrates, the mother answered the health nurse's questions that were addressed verbally to both parents first in $72 \%$ of cases. This occurred in three different contexts: 1) the mother is selected as respondent by all participants, 2) the mother self-selects as respondent, and 3 ) the mother ends up answering because the father does not take the responding turn allocated to him through gaze.

\subsubsection{The mother is selected as respondent by all participants $(n=49)$}

The most typical case in the data was that all participants treated the mother as the principal respondent to the health nurse's question verbally addressed to both parents: the health nurse gazed at the mother or the questionnaire filled in by the mother, the mother answered and the father remained silent and in some cases looked at the mother. Example 1, presented in Figure 1 , is a case in point. The parents who are on their first visit to the clinic have just entered the consultation room and taken a seat. The health nurse asks if the client couple is expecting their first child (line 1). (See Appendix for the key to transcript symbols.) 


\section{Figure 1: Example (translated from Finnish)}

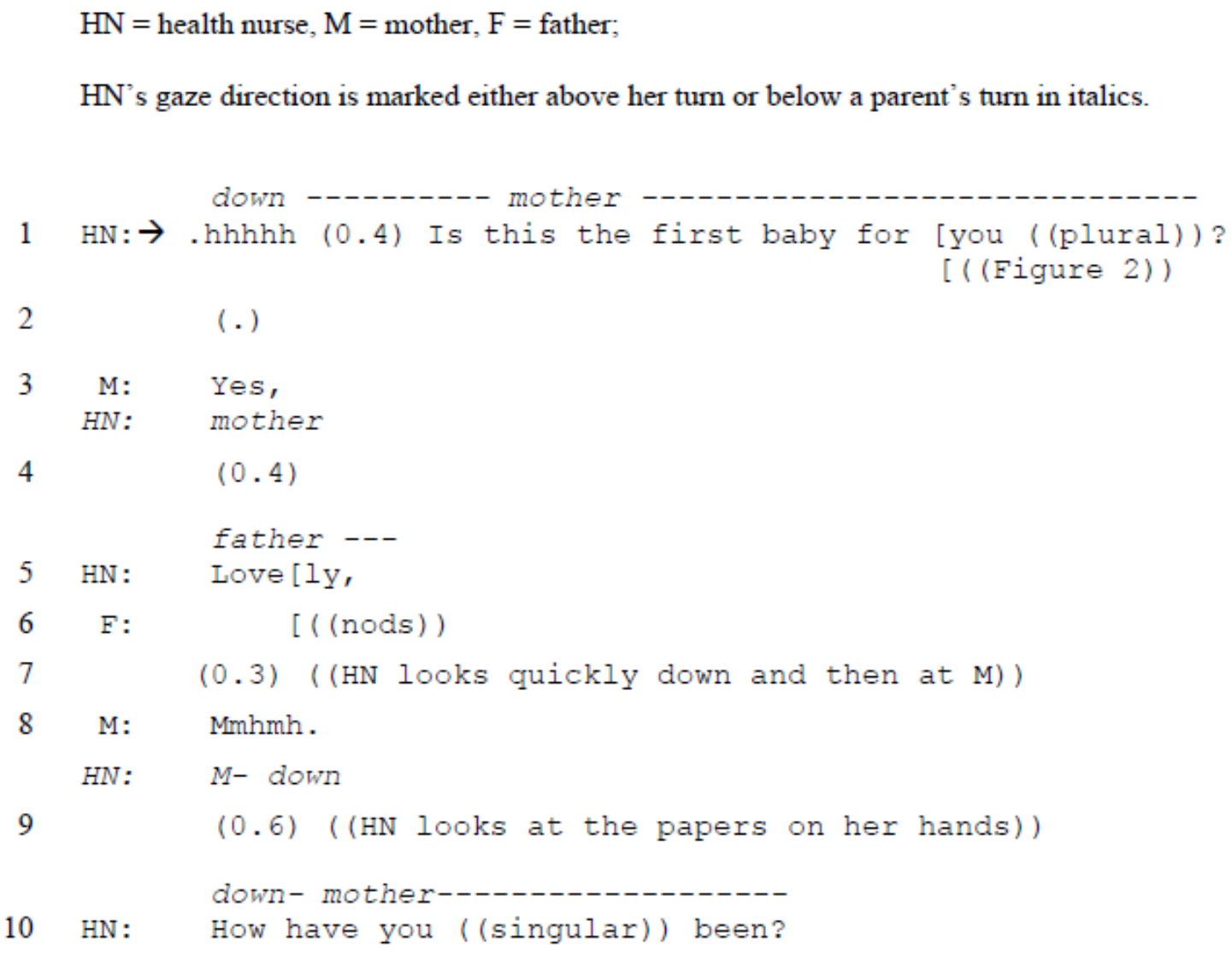

In line 1, the health nurse is turning her gaze from the papers towards the mother while posing the question (Figure 2). Thus the health nurse addresses the mother with her gaze and so treats the mother as the principal respondent to the question, which could have been answered by the father as well. The mother answers the question in line 3 . While commenting on the mother's affirmative answer by saying "lovely", the health nurse quickly glances at the father who at that point responds by nodding. This shows that the father is indeed attentive to what is being talked about. However, by letting the mother answer the question, the father shows that he also treats the mother as the principal respondent.

The previous extract is an example of the typical cases where the health nurse gazed at the mother at the TRP and thus addressed the question principally to the mother. In addition, in some cases, the health nurse's gaze at the preliminary information form or at the questionnaire about psycho-social issues filled in by the mother reinforced the significance of the immediate context of going through the questionnaire as allocating the principal responding turn to the mother. 


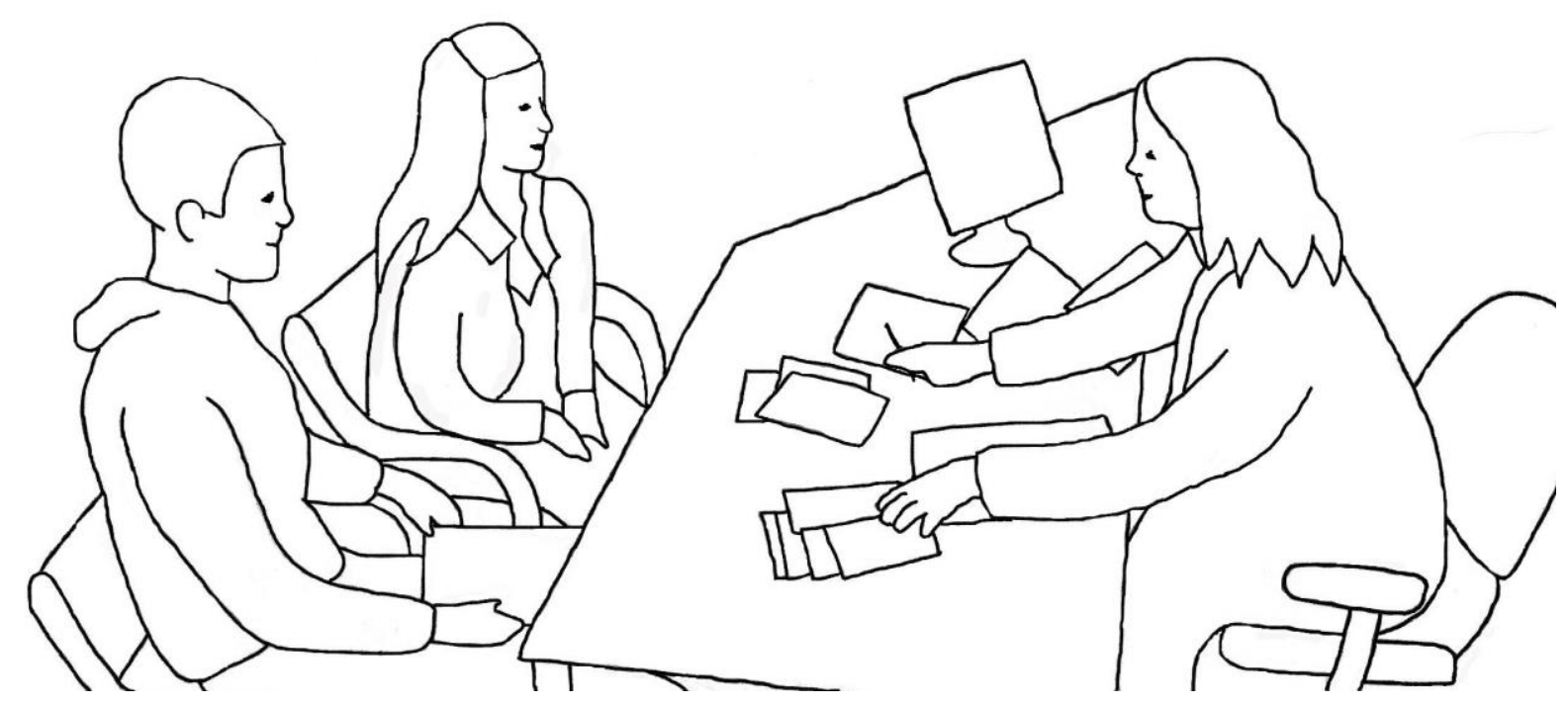

\subsubsection{The mother self-selects as respondent $(n=11)$}

In 11 cases, the mother selected herself to respond without any direct encouragement by the health nurse when the nurse was not gazing at her or the questionnaire she filled in. The mother's self-selection was explainable by reference to a) the macro context of maternity clinics and $b$ ) the sequential context of two-party conversations. For example, common opening questions like "how are you" at the beginning of the encounters were usually heard in the data in relation to the pregnancy. In the maternity clinic, the mother may well see herself as the principal respondent because she carries the baby and thus has more first-hand information about the pregnancy.

In addition, the turn-taking organization itself may contribute to the sequential context in which the mother self-selects, since it favors the conversations of two parties, namely the current and the next speaker. Thus, for example, if the mother has answered one question and the health nurse immediately asks another question about the same topic, it may be heard by the participants as a contingent question addressed to the immediately previous speaker by virtue of the turn-taking organization regardless of the verbal design of the question. [30]

\subsubsection{The mother ends up answering because the father does not take the responding turn allocated to him through gaze $(n=4)$}

Almost every time the health nurse allocated the principal responding turn to the mother, the father also oriented to the priority of the mother and let her answer first. In addition, the data contained four cases in which the health nurse addressed the father by gazing at him, but the father treated the mother as the principal respondent and did not take the responding turn allocated to him. This orientation to the mother as the principal respondent by the father may reflect his more general orientation to the maternity clinic as interested only in the mother. These cases demonstrate the limits of gaze direction as a turn-allocation technique. 
In 25 cases, the father answered the question first or at the same time as the mother. These cases deviated from the typical pattern of the mother answering first. This occurred in two different contexts: 1) the father ends up answering because of situational elements, and 2) the father self-selects or is selected as respondent.

\subsubsection{The father ends up answering because of situational elements $(n=14)$}

In more than half the cases in which the father answered first, the health nurse had selected the mother as the principal respondent and the father ended up answering for situational reasons. Table 2 sums up these situational elements.

Table 2: Situational elements explaining why the father answers first or at the same time as the mother although the health nurse selects the mother as the principal respondent

\begin{tabular}{|c|c|}
\hline 1) the father does not see the health nurse's gaze at the mother & 6 \\
\hline 2) the mother's answer has been discussed already & 4 \\
\hline 3) the question has been addressed to the mother first & 2 \\
\hline 4) the mother turns to gaze at the father & 2 \\
\hline total & 14 \\
\hline
\end{tabular}

First, the most common situational element which explains why the father answered the question first even though the mother was selected as the principal respondent by the health nurse was that the father was looking away and did not see that the health nurse was gazing at the mother. All of these cases were from the encounters in which the questionnaire about psycho-social issues was discussed. This context seems to be relevant for the self-selection by the father, and we further elaborate on this relevance in the next section.

Second, there were four cases in the data in which the father was selected as the principal respondent to the question but the mother had already been asked about the same topic. For example, in one of these cases, the health nurse is discussing diet with the mother and it has emerged that the mother is a vegetarian. In the middle of this discussion between the health nurse and the mother, the health nurse says "te ootte kummakki", you both are, presuming [31] that both parents are vegetarians. While asking this question the health nurse gazes at the father. However the gaze does not indicate that the father is the principal respondent to a question concerning both parents, since it is already known that the mother is a vegetarian and this question addressed to the father only inquires whether the father has the same diet as the mother.

Third, there were two cases in the data in which the health nurse first addressed the mother with her gaze but then turned to gaze at the father because the mother did not make the responding move.

Fourth, there were two cases in the data in which the father's first answer can be explained by the mother (who was addressed by the health nurse) passing the turn of talk to father by turning to gaze at him. These cases demonstrate especially well how turn-allocation in threeparty interaction is negotiated by all participants. 


\subsubsection{The father self-selects or is selected as respondent $(n=11)$}

So far, we have discussed the cases in which the mother answered first and then the cases in which the father answered first but the mother had been selected as the principal respondent by the health nurse. The remaining 11 cases deviated from the pattern of selecting the mother as the principal respondent.

Nine out of the 11 deviant cases were from two encounters in which the new questionnaire about psycho-social issues was being discussed. This suggests that the questionnaire is potentially an important tool in engaging both parents in discussion. They both fill in a similar questionnaire before the encounter which indicates to them that the health nurse is equally interested in the answers of both.

The two remaining deviant cases occurred in situations in which the father had been treated as an equal client just before the question. In one case, the father and the health nurse meet for the first time (although it is nearly the expected date of the delivery). The health nurse chats with the father at the beginning of the encounter which creates a basis for the father's participation. He takes an active role in commenting on the subsequent conversation, and the health nurse addresses him through gaze. In the other remaining deviant case, the father selfselects when the health nurse is not gazing at the parents. This occurs after the sequence in which the health nurse has talked about prenatal classes and engaged both parents in turn through gaze. These cases highlight the relevance of the situational context for the turnallocation.

The analysis made observable the pattern that mothers are typically selected as principal respondents by all participants in our data from maternity clinics. The deviant cases, however, indicated that in particular circumstances and with particular interactional practices the pattern that preserves the principal role of the mother can be broken.

\section{Discussion and Conclusion}

\subsection{Discussion}

A key result of this study was that the health nurse may address both parents verbally and at the same time address only one of the parents with gaze. The significance of gaze in turnallocation has been demonstrated in studies of ordinary conversations [20-23] and the patientdirected gaze has also been noted as relevant in health care encounters [32-36]. This analysis contributes to our knowledge of the interactional consequences of gaze direction especially in multi-client health care encounters. It shows how a simple non-verbal orientation to the next speaker through gaze-direction may have significant consequences in terms of participation in the conversation. This observation illuminates one central aspect of enhancing client participation. Further, the analysis demonstrates the limits of gaze direction as a turnallocation technique as various situational elements construct a context for speaker selection.

We also demonstrated how both parents may orient to the mother's priority as a responsible parent in the clinic. In spite of the targets of family-centeredness in clinics, many parents still support the traditional idea that the mother has the primary responsibility for childcare and the father is the primary breadwinner. [37,11] At the same time, however, many parents want to share parental responsibilities equally and many new interventions (such as the questionnaires mentioned) have been developed to encourage fathers to take more responsibility as parents. 
Our research suggests that the engagement of fathers in conversation about pregnancy and child care as well as about the psycho-social issues involved may ultimately depend on the ways in which conversation is conducted with them, since the expectations of and demands imposed on fathers by representatives of child health care are displayed in their mutual encounters. Treating only mothers as principal respondents on issues of child care and parenting may well signal to fathers that their role as a parent is expected to be marginal.

\subsection{Conclusion}

The basis for supporting both parents in the transition to parenthood is a trustful relationship between the client family and the professionals in the clinics. We illustrated a trend towards orienting to the mother as the principal client in the clinics, and this result is consistent with the previous interview studies [8-11]. In addition to spotting the trend, this study highlighted the ways in which the non-verbal component of gaze direction makes it possible to engage fathers in discussions in maternity clinics. We demonstrated how the role of the mother as the principal respondent to the health nurses' questions is reconstructed by minute practices of non-verbal communication. These communication practices supporting the role of the mother as the principal client in the maternity clinics can potentially marginalize the role of the father as a responsible and competent parent in the family. The deviant cases, however, suggest that there are ways in which this pattern can be broken and that fathers can be treated as equally responsible parents.

The interactional practice of turn-allocation through gaze and the interactional circumstances that influence the practice described in this study are generalizable to conversations in maternity clinics - and potentially to other three-party conversations in clinical settings - as "possibilities of language use" [38], i.e. a possible technique of allocating turns of talk to parents and its possible limitations. Our qualitative analysis offers a starting point - an empirically observable sequence of conversation - for future quantitative research on the prevalence of both verbal and non-verbal interactional elements in maternity and child health care encounters. Future studies on the turn-allocation patterns at the beginning of the encounter and their significance for the rest of the encounter would be especially beneficial, as this study demonstrates the relevance of the sequential context of the question as a part of the ongoing discussion.

\subsection{Practice Implications}

Acknowledging the significance of gaze direction in addressing questions is of great importance. The transition relevance places especially, such as the closure of the question, are important in addressing a particular parent as the respondent. By simply paying attention to their gaze direction the professionals can engage clients in conversation. Our analysis also demonstrates the potential of the questionnaire filled in by both parents. The questionnaire is not only a suitable means to help screen for psycho-social risk but also seems promising in engaging both parents in discussion in the clinics.

Previous reports on maternity and child health care clinics have pointed out that the question of supporting fathers in clinics is important. Various methods have been developed for this purpose. These include private encounters and discussion groups for fathers and special materials targeted at them. [3, 39] All these methods are relevant but the extra resources required are not always available. Engaging fathers in conversation through gaze, in 
encounters in which they are already present, is an easy and inexpensive way to highlight their equal role not only as a client of the maternity clinic but also as a parent.

\section{Acknowledgements:}

The article is a part of a doctoral thesis funded by the Finnish Doctoral Program in Social Sciences (SOVAKO). The data was collected in course of the research project that has had two grants from Juho Vainio Foundation.

\section{Appendix}

Key to transcript symbols developed by Gail Jefferson [13].

$\begin{array}{ll}?, . & \text { rising / continuing / falling intonation } \\ (0.4) & \text { pause } \\ \text { hh } & \text { inbreath } \\ \text { [ } & \text { overlap }\end{array}$

\section{References}

[1] Glass N. Sure Start: the development of an early intervention programme for young children in the United Kingdom. Child Soc 1999;13:257-64.

[2] Armstrong C, Hill M. Support services for vulnerable families with young children. Child Fam Soc Work 2001;6:351-8.

[3] Ministry of Social Affairs and Health. Lastenneuvola lapsiperheiden tukena. Opas työntekijöille [Child health clinics in support of families with children. A guide for staff]. Helsinki: Ministry of Social Affairs and Health, 2004. Finnish.

[4] Condon JT, Boyce P, Corkindale CJ. The First-Time Fathers Study: a prospective study of the mental health and wellbeing of men during the transition to parenthood. Aust $\mathrm{N} \mathrm{Z} \mathrm{J}$ Psychiatry 2004;38:56-64.

[5] Fägerskiöld A. A change in life as experienced by first-time fathers. Scand J Caring Sci 2008;22:64-71.

[6] Finnbogadottir H, Crang Svalenius E, Persson EK. Expectant first-time fathers' experiences of pregnancy. Midwifery 2003;19:96-105.

[7] Matthey S, Barnett B, Ungerer J, Waters B. Paternal and maternal depressed mood during the transition to parenthood. J Affect Disord 2000;60:75-85.

[8] Mesiäislehto-Soukka H. Perheenlisäys isien kokemana: fenomenologinen tutkimus [Phenomenological study of fathers' experiences of family life after the birth of a baby] [dissertation]. Oulu: University of Oulu, 2005. Finnish. 
[9] Paavilainen R. Turvallisuutta ja varmuutta lapsen odotukseen. Äitien ja isien kokemuksia raskaudesta ja äitiyshuollosta [Feeling safe and secure during pregnancy. Mothers' and fathers' experiences of pregnancy and maternity health care] [dissertation]. Tampere: University of Tampere, 2003. Finnish.

[10] Fägerskiöld A. Support of fathers of infants by the child health nurse. Scand J Caring Sci 2006;20:79-85.

[11] Kaila-Behm A, Vehviläinen-Julkunen K. Ways of being a father: how first-time fathers and public health nurses perceive men as fathers. Int J Nurs Stud 2000;37:199-205.

[12] Berger PL, Luckmann T. The social construction of reality: a treatise in the sociology of knowledge. Harmondsworth: Penguin, 1984.

[13] Heritage J. Garfinkel and Ethnomethodology. Cambridge: Polity Press, 1984.

[14] Äitiys- ja lastenneuvola [Maternity and child health care clinics] [Internet]. Helsinki: National Institute for Health and Welfare (THL); [2012; cited 2012 Apr 4]. Available from: http://www.thl.fi/fi_FI/web/kasvunkumppanit-fi/palvelut/aitiys_ja_lastenneuvola/. Finnish.

[15] Viisainen K, ed. Seulontatutkimukset ja yhteistyö äitiyshuollossa. Suositukset 1999 [Screening and co-operation in prenatal care. Recommendations 1999]. Helsinki: Stakes, 1999. Finnish.

[16] Roter D, Larson S. The Roter interaction analysis system (RIAS): utility and flexibility for analysis of medical interactions. Patient Educ Couns 2002;46:243-51.

[17] Zimmermann C, Del Piccolo L, Bensing J, Bergvik S, De Haes H, Eide H, Fletcher I, Goss C, Heaven C, Humphris G, Kim YM, Langewitz W, Meeuwesen L, Nuebling M, Rimondini M, Salmon P, van Dulmen S, Wissow L, Zandbelt L, Finset A. Coding patient emotional cues and concerns in medical consultations: The Verona coding definitions of emotional sequences (VR-CoDES). Patient Educ Couns 2011;82:141-8.

[18] Connor M, Fletcher I, Salmon P. The analysis of verbal interaction sequences in dyadic clinical communication: A review of methods. Patient Educ Couns 2009;75:169-77.

[19] Heritage J, Maynard DW. Introduction: Analyzing interaction between doctors and patients in primary care encounters. In: Heritage J, Maynard DW, eds. Communication in Medical Care: Interaction between Primary Care Physicians and Patients. Cambridge: Cambridge University Press, 2006:1-21.

[20] Lerner GH. Selecting next speaker: the context-sensitive operation of a context-free organization. Lang Soc 2003;32:177-201.

[21] Kendon A. Conducting interaction: Patterns of behavior in focused encounters. Cambridge: Cambridge University Press, 1990.

[22] Kalma A. Gazing in triads: A powerful signal in floor apportionment. Br J Soc Psychol 1992;31:21-39.

[23] Goodwin C. Restarts, Pauses, and the Achievement of a State of Mutual Gaze at TurnBeginning. Sociol Inq 1980;50:272-302.

[24] Schegloff EA. On some questions and ambiguities in conversation. In: Atkinson JM, Heritage J, eds. Structures of Social Action: Studies in Conversation Analysis. Cambridge: Cambridge University Press, 1984;28-52.

[25] Schegloff EA. Parties and Talking Together: Two Ways in Which Numbers Are Significant for Talk-in-Interaction. In: ten Have P, Psathas G, eds. Situated Order: Studies in 
the Social Organization of Talk and Embodied Activities. Washington D.C.: University Press of America, 1995;31-42.

[26] Lerner GH. Collectivities in action: Establishing the relevance of conjoined participation in conversation. Text 1993;13:213-45.

[27] Heritage J. Conversation Analysis: Methodological Aspects. In: Quasthoff UM, ed. Aspects of Oral Communication. Berlin: Walter de Gruyter, 1995;391-418.

[28] Stivers T, Enfield NJ, Brown P, Englert C, Hayashi M, Heinemann T, Hoymann G, Rossano F, de Ruiter JP, Yoon KE, Levinson SC. Universals and cultural variation in turntaking in conversation. Proc Natl Acad Sci USA 2009;106:10587-92.

[29] Maynard DW, Clayman SE. Ethnomethodology and conversation analysis. In: Reynolds LT, Herman-Kinney NJ, eds. Handbook of Symbolic Interactionism. Walnut Creek, CA: Altamira Press, 2003;173-202.

[30] Sacks H, Schegloff EA, Jefferson G. A Simplest Systematics for the Organization of Turn-Taking for Conversation. Language 1974;50:696-735.

[31] Pomerantz A. Offering a Candidate Answer: An Information Seeking Strategy. Commun Monogr 1988;55:360-73.

[32] Bensing JM, Kerssens JJ, van der Pasch M. Patient-directed gaze as a tool for discovering and handling psychosocial problems in general practice. J Nonverbal Behav 1995;19:223-42.

[33] Caris-Verhallen W, Kerkstra A, Bensing JM. Non-verbal behaviour in nurse-elderly patient communication. J Adv Nurs 1999;29:808-18.

[34] Ruusuvuori J. Looking means listening: coordinating displays of engagement in doctorpatient interaction. Soc Sci Med 2001;52:1093-108.

[35] Stivers T. Negotiating Who Presents the Problem: Next Speaker Selection in Pediatric Encounters. J Commun 2001;51:252-82.

[36] Gorawara-Bhat R, Cook MA. Eye contact in patient-centered communication. Patient Educ Couns 2011;82:442-7.

[37] Lammi-Taskula J. Doing Fatherhood: Understanding the Gendered Use of Parental Leave in Finland. Fathering 2008;6:133-48.

[38] Peräkylä A. Reliability and validity in research based on naturally occurring social interaction. In: Silverman D, ed. Qualitative Research: Theory, Method and Practice. 2nd ed. London: Sage, 2004;283-304.

[39] Ministry of Social Affairs and Health: Isien ja isyyden tukeminen äitiys- ja lastenneuvoloissa [Support for fathers and fatherhood at maternity and child health clinics]. Helsinki: Ministry of Social Affairs and Health, 2008. Finnish. 